\title{
DETERMINANT FACTORS OF STUNTING AND EFFECTIVENESS OF NUTRITION, INFORMATION, EDUCATION INTERVENTIONS TO PREVENT STUNTING IN THE FIRST 1000 DAYS OF LIFE: A SYSTEMATIC REVIEW
}

\author{
Basri Aramico, Emy Huriyati, Susetyowati, Fatwa Sari Tetra Dewi \\ Faculty of Medicine, Universitas Muhammadiyah Aceh
}

\begin{abstract}
Background: In the world, stunted children reach 155 million, with a 23\% stunting prevalence. Asia as a whole is the most heavily stunted region in the world. In Asia, the prevalence of stunting was $56 \%$ in 2016. In 2019, the world's number of stunted children reached 144 million, or $21.3 \%$. Stunted children will experience neurological problems in the first 1000 days of life. This study aimed to systematically review the determinants factors of stunting and effectiveness of nutrition, information, education interventions to prevent stunting in the first 1000 days of life.

Subjects and Method: This was a systematic review study. Articles selected in this study were published in the PubMed database from January 2010 to January 2020. The articles were collected by following the Preferred Reporting Items of Systematic Reviews and Meta-Analysis (PRISMA).

Results: Determinant factors of stunting in developing countries and low-middle income countries were 1) feeding practice; 2) culture and ethnicity; delayed in carrying out early initiation of breastfeeding and complementary feeding of breast milk; 3) lack of knowledge and understanding of mothers about complementary breastfeeding and infant diet; 4) family planning practice; 5) birth spacing; 6) vaccination; 7) and parent's education.

Conclusion: Handling stunting in the first 1000 days of life is a priority at the national and global levels. Efforts to handle and prevent stunting problems through increasing maternal nutrition knowledge can be done by providing information or health messages related to nutrition, from a person or institution to the community as message recipients through certain media
\end{abstract}

Keywords: determinant, intervention, golden age, stunting

\section{Correspondence:}

Basri Aramico. Faculty of Medicine, Universitas Muhammadiyah Aceh.

Email: basri.aramico@yahoo.com 